\title{
Erratum zu: Agilität, Ambidextrie und organisationale Veränderungskompetenz. Rudi Wimmer über Erbe und Zukunft des Change Managements
}

\author{
Rudi Wimmer ${ }^{1} \cdot$ Falko von Ameln ${ }^{2}$ \\ Online publiziert: 15. Januar 2020 \\ ๑) Springer Fachmedien Wiesbaden GmbH, ein Teil von Springer Nature 2020
}

\section{Erratum zu:}

\section{Gr Interakt Org 2019}

https://doi.org/10.1007/s11612-019-00458-0

Der Artikel „Agilität, Ambidextrie und organisationale Veränderungskompetenz. Rudi Wimmer über Erbe und Zukunft des Change Managements" von Rudi Wimmer und Falko von Ameln wurde ursprünglich ohne „Open Access“ Online First auf der Internetplattform des Verlags publiziert. Nach der Veröffentlichung im Band 50 Heft 2 pp 211-216 entschieden sich die Autoren nachträglich für eine „Open Access"-Veröffentlichung. Das Urheberrecht des Artikels wurde deshalb zu () Der/die Autor(en) 2019 geändert. Der Artikel wird nun unter der Namensnennung 4.0 International (https://creativecommons.org/licenses/by/4.0/deed.de) veröffentlicht, welche die Nutzung, Vervielfältigung, Bearbeitung, Verbreitung und Wiedergabe in jeglichem Medium und Format erlaubt, sofern Sie den/die ursprünglichen Autor(en) und die Quelle ordnungsgemäß nennen, einen Link zur Creative Commons Lizenz beifügen und angeben, ob Änderungen vorgenommen wurden.

Die Online-Version des Originalartikels ist unter https://doi.org/ 10.1007/s11612-019-00458-0 zu finden.

\footnotetext{
Univ.-Prof. Dr. Rudi Wimmer

rudolf.wimmer@osb-i.com

PD Dr. Falko von Ameln

info@vonameln.net

1 osb Wien Consulting GmbH, Volksgartenstraße

3/1.DG, 1010 Wien, Österreich

2 Leipziger Str. 9, 26506 Norden, Deutschland
} 